\title{
Vertical variations of soil moisture in response to vegetation restoration on the Loess Plateau of China
}

\author{
dexun $\mathrm{Qiu}^{1}$, Peng $\mathrm{Gao}^{2}$, Xingmin $\mathrm{Mu}^{3}$, and Baili $\mathrm{ZHao}^{4}$ \\ ${ }^{1}$ Institute of Soil and Water Conservation Chinese Academy of Sciences and Ministry of \\ Water Resources \\ ${ }^{2}$ Northwest A\&F University \\ ${ }^{3}$ Institute of Soil and Water Conservation \\ ${ }^{4}$ Northwest Agriculture and Forestry University
}

November 27, 2020

\begin{abstract}
Soil moisture is essential for vegetation restoration in arid and semi-arid regions. Ascertaining the vertical distribution and transportation of soil moisture under different vegetation restoration types has a profound impact on the ecological construction. In this study, the soil moisture at a depth of $500 \mathrm{~cm}$ for four typical vegetation types, including R. pseudoacacia (forestland), C. korshinskii (shrubland), S. bungeana (abandoned land), and corn (cropland) were investigated and compared in the Zhifanggou watershed of Loess plateau, China. Additionally, hydrogen and oxygen stable isotopes were detected to identify and reflect the characteristics of soil water. The results showed vertical distribution and transportation of soil moisture have different variations under different vegetation types. Depth-averaged soil moisture under S. bungeana and corn increased along the profile as a whole, while C. korshinskii and R. pseudoacacia showing a trend of weakly increasing and relatively stable state after an obvious decreasing trend $(0-40 \mathrm{~cm})$. The mean soil moisture under R. pseudoacacia is lower than other types, especially in deeper layers. In addition, it was observed that the longer vegetation age, the lower mean soil moisture, while this phenomenon was unobvious in S. bungeana. Planting arbor species such as R. pseudoacacia intensified the decline of soil moisture in the Loess Plateau, this limited the growth of arbor species in turn. The capacity of evaporation fractionation of soil moisture followed the sequence: corn $>$ S. bungeana $>$ R. pseudoacacia $>$ C. korshinskii. Profiles of $\delta 18 \mathrm{O}$ values of soil moisture under different vegetation types are quite different. On the whole, the $\delta 18 \mathrm{O}$ values varied greatly in upper soil layers and tend to be consistent with the increase of soil depth. We estimate that piston flow is the main mode of precipitation infiltration, and the occurrence of preferential flow is related to vegetation types. These results are expected to help improve the understanding of the response of deep soil moisture to vegetation restoration and inform practices for sustainable water management.
\end{abstract}

\section{Hosted file}

Manuscript.pdf available at https://authorea.com/users/379370/articles/495592-verticalvariations-of-soil-moisture-in-response-to-vegetation-restoration-on-the-loess-plateauof-china 

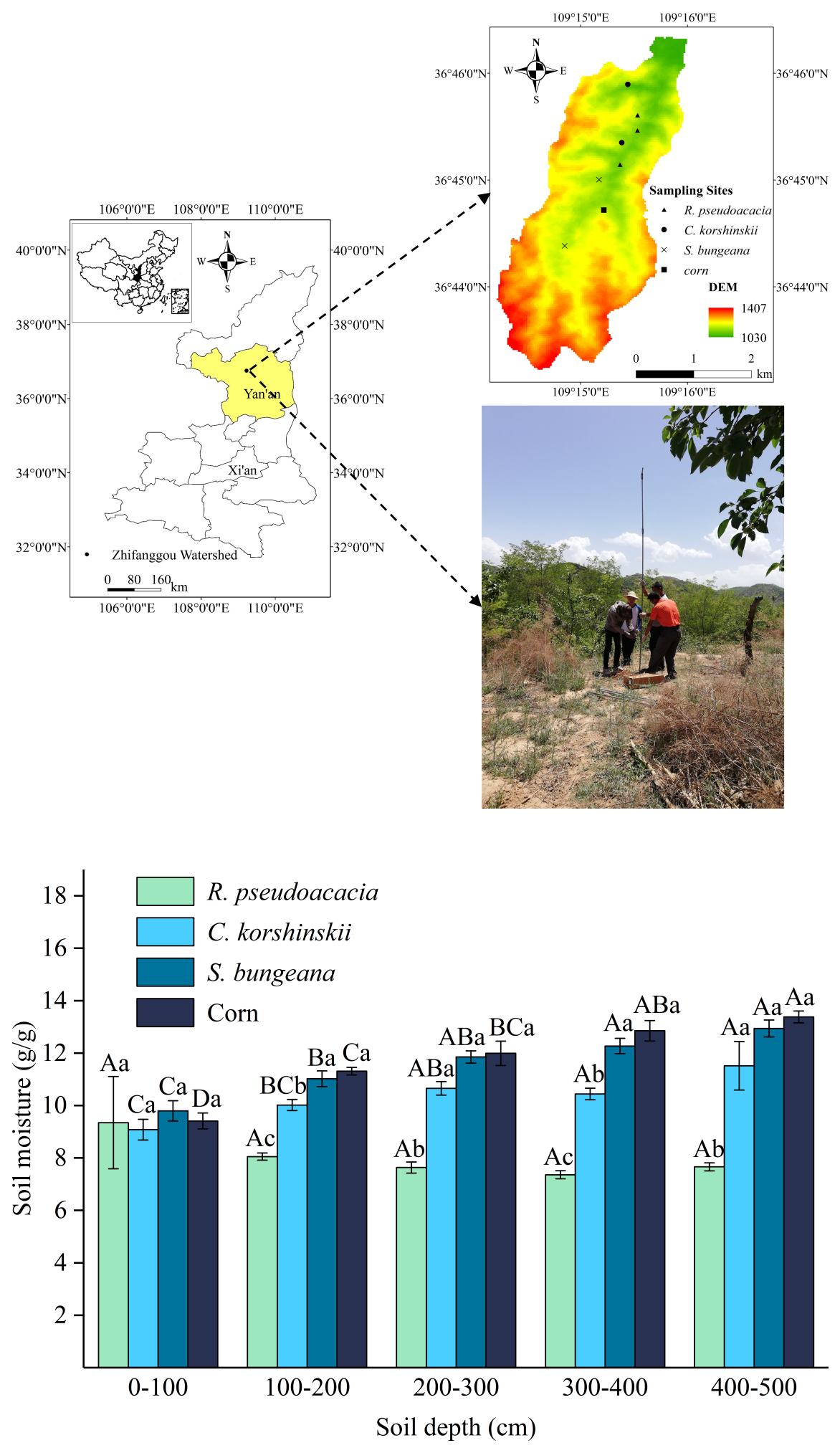

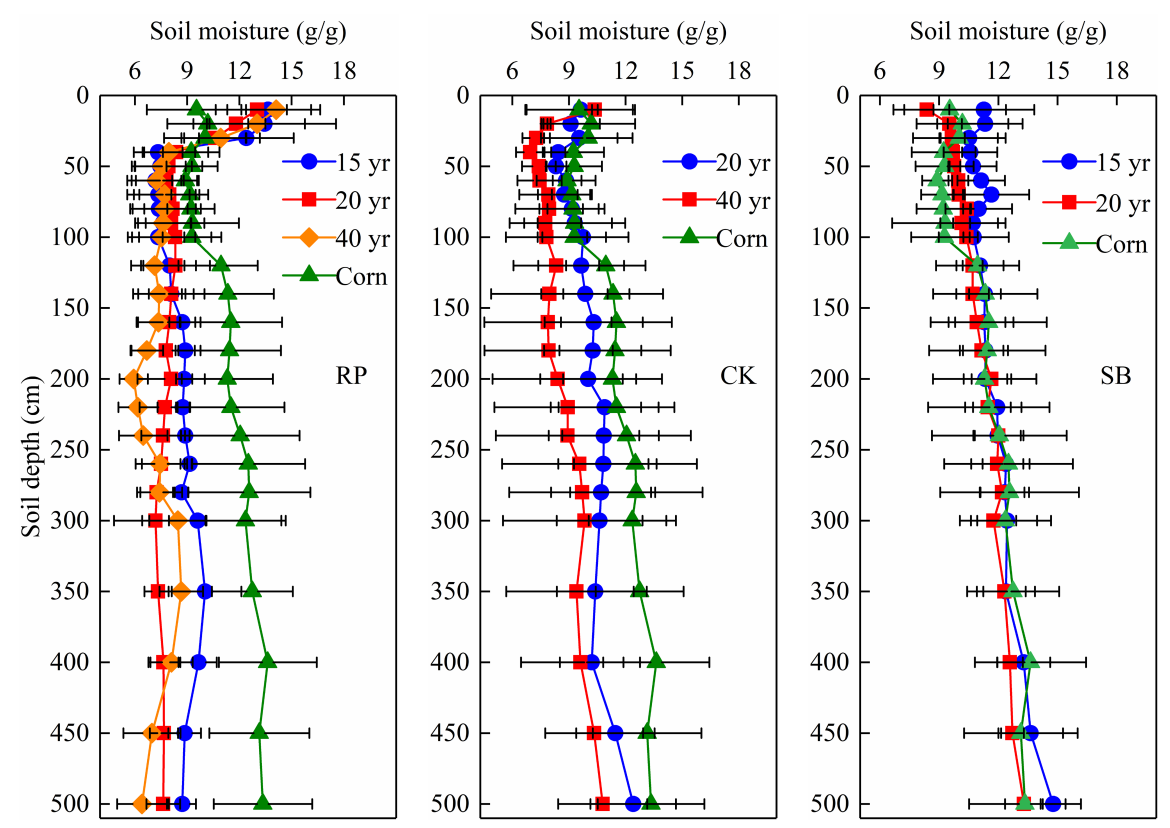

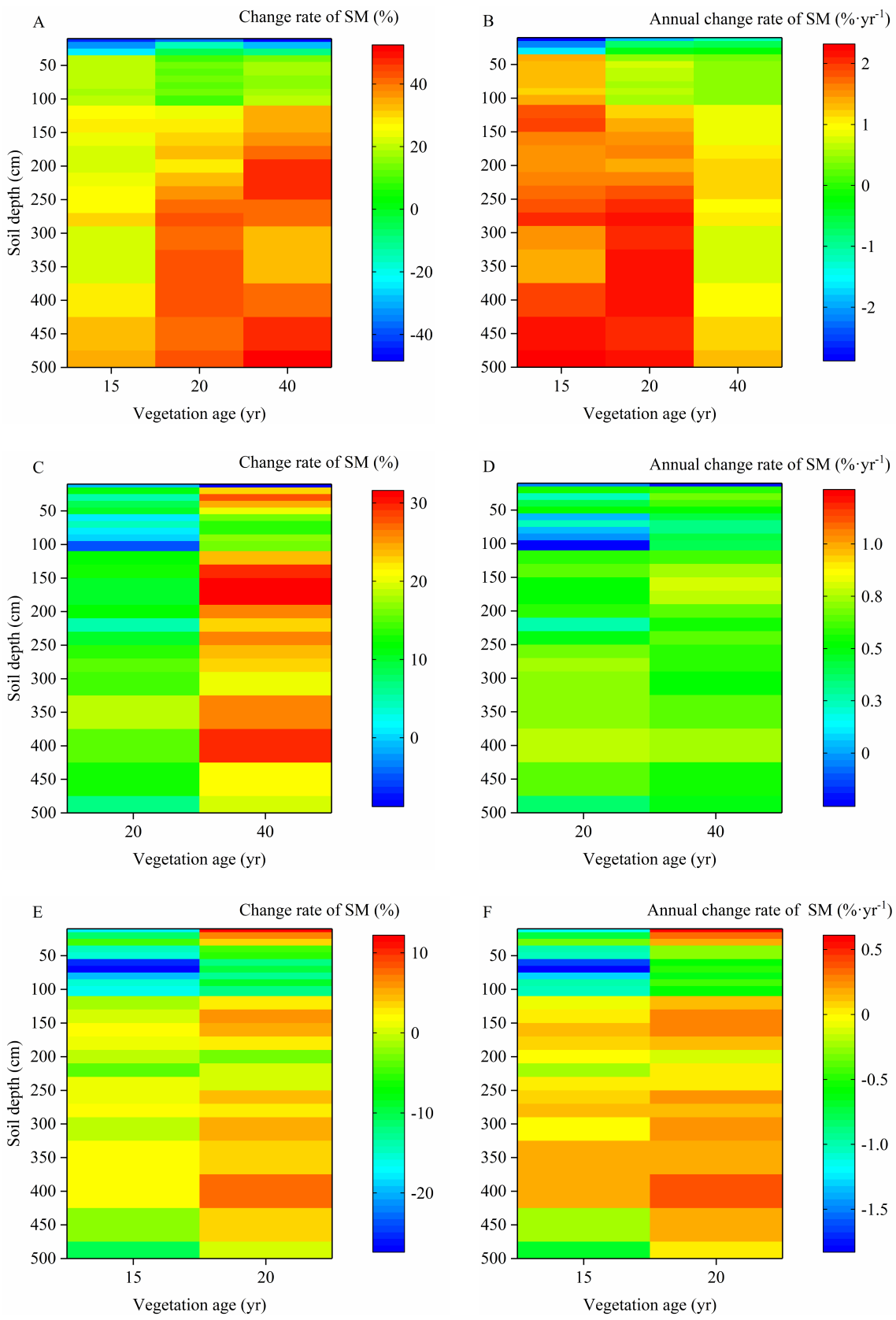


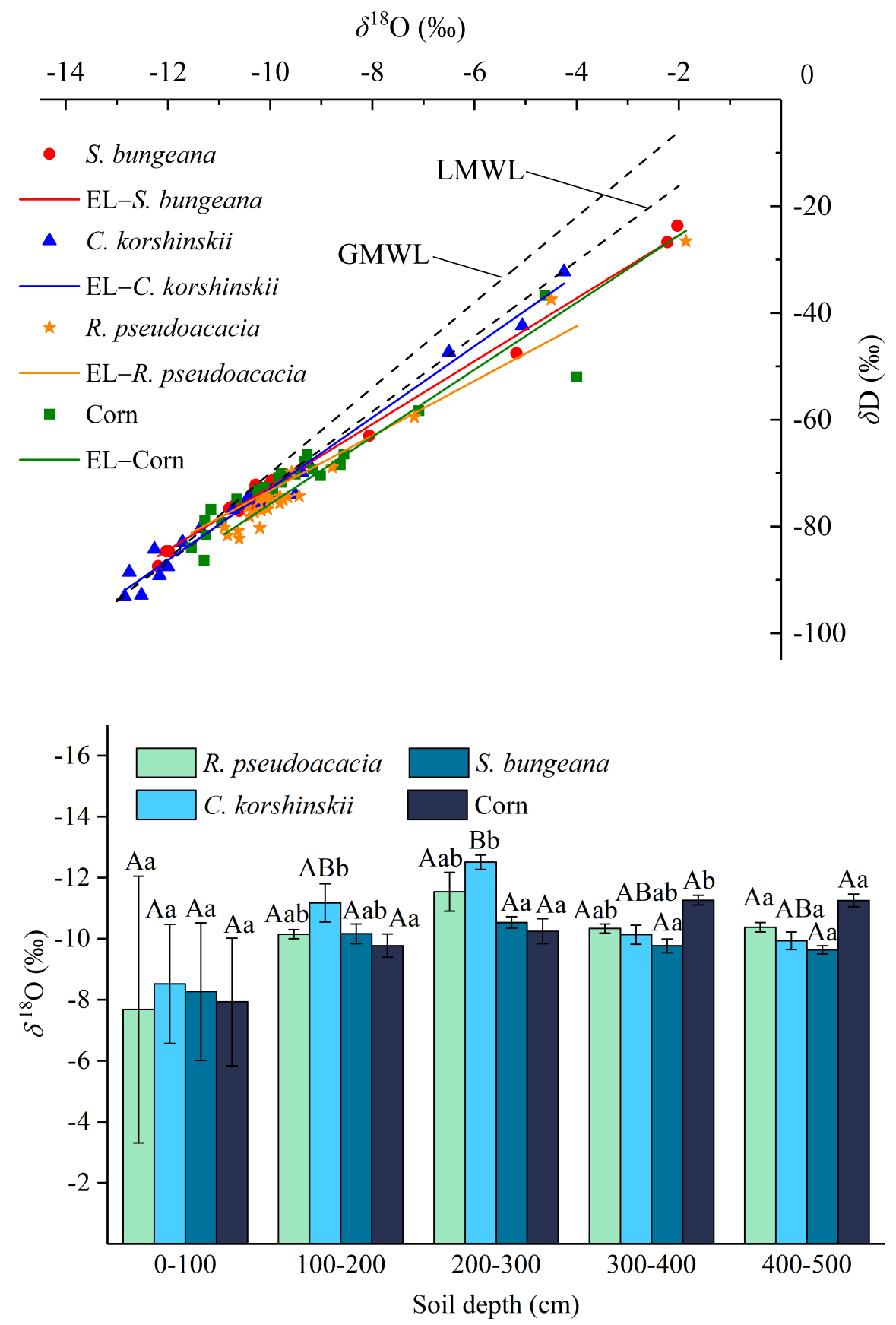



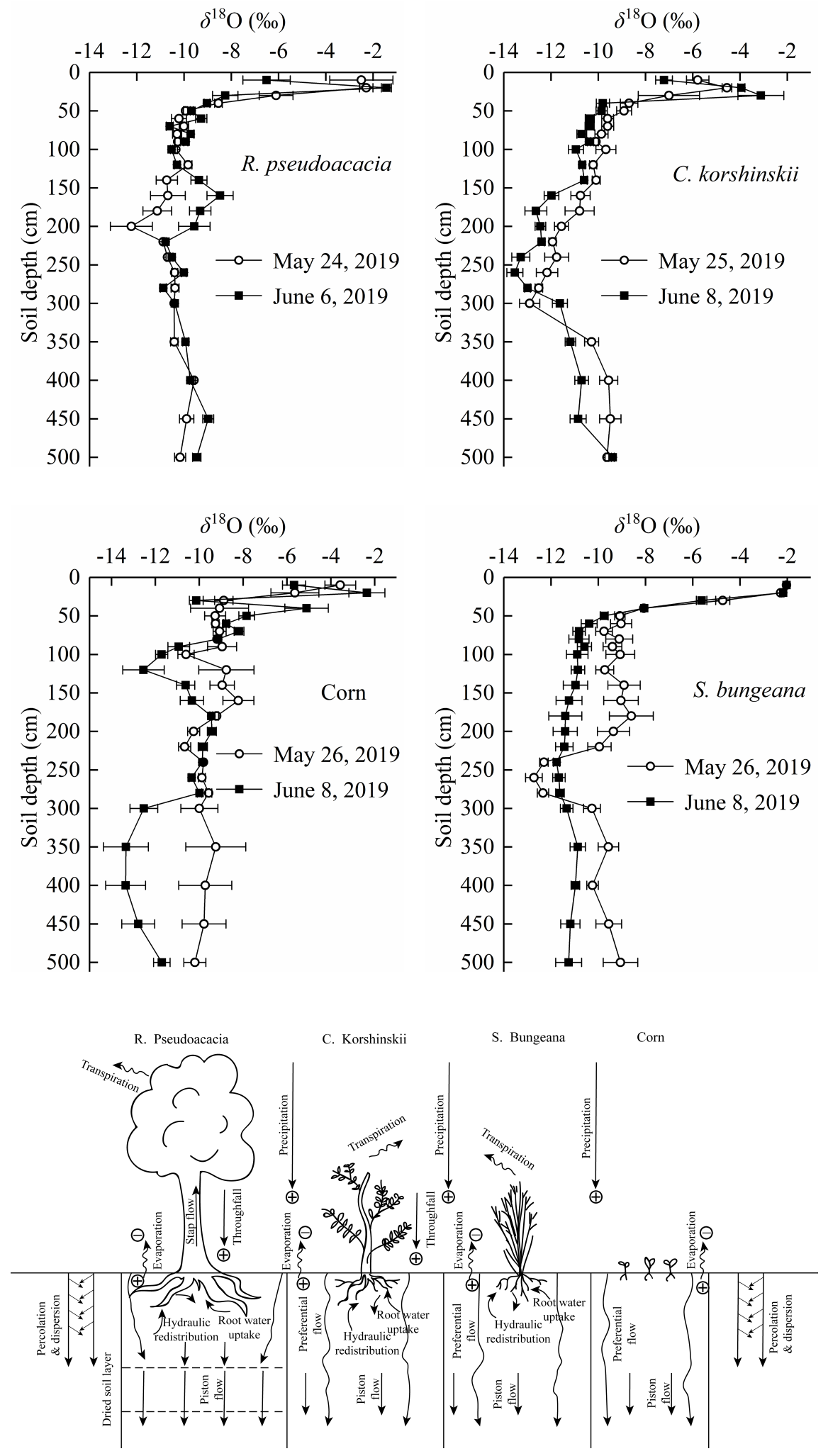